\title{
Chronic kidney disease in pregnancy and fetomaternal outcome
}

\author{
Pooja Gupta*, Indu Chawla, Anjum Ara, Renuka Malik
}

Department of Obstetrics and Gynecology, PGIMER and Dr. R. M. L. Hospital, New Delhi, India

Received: 09 August 2019

Accepted: 19 August 2019

\section{*Correspondence:}

Dr. Pooja Gupta,

E-mail: drpoojagupta1@gmail.com

Copyright: ( ) the author(s), publisher and licensee Medip Academy. This is an open-access article distributed under the terms of the Creative Commons Attribution Non-Commercial License, which permits unrestricted non-commercial use, distribution, and reproduction in any medium, provided the original work is properly cited.

\section{ABSTRACT}

Background: Chronic kidney disease is a heterogeneous group of renal dysfunctions with complex and varied presentations in pregnancy. With a long asymptomatic course, timely diagnosis and management is crucial for fetomaternal wellbeing.

Methods: A retrospective cohort study over a period of 3 years and 4 months included all obstetric in patients with known or newly diagnosed renal disorders. Maternal outcome was measured with regard to biochemical parameters presence /absence of proteinuria, hypertension, mode of pregnancy termination and complications. Fetal outcome was noted with respect to antenatal complications, weight, Apgar, NICU stay. Computation of results was done using percentages, mean and proportions.

Results: Out of 13 women studied, 53.8\% were pre-diagnosed cases of renal dysfunction and $46.2 \%$ were diagnosed during pregnancy. $38 \%$ had proteinuria at first visit and 50\% remained so even after delivery. $60 \%$ had history of pregnancy induced hypertension in their previous pregnancies. Secondary hypertension and superimposed preeclampsia were seen in $30 \%$ and $38 \%$ cases respectively, with only one patient requiring magnesium sulphate prophylaxis in post-partum. Cardiac dysfunction was found to be coexisting in $15.3 \%$ cases with pre-existing renal leision. Intrauterine growth restriction was seen in $61.5 \%$ cases Average fetal weight was 2. $26 \mathrm{~kg}$ with $30 \%$ having NICU stay. $30.6 \%$ had preterm delivery. Mode of delivery was caesarean section in $46 \%$ cases.

Conclusions: Pregnancy with CKD is a high-risk pregnancy with adverse fetomaternal outcomes. For optimal pregnancy outcomes, an expert multidisciplinary team is required. With limited studies in south Asian population, there needs to be an upgradation in registry system.

Keywords: Acute kidney failure, Cardiac failure, Obstetric nephrology, Pregnancy, Premature, Stillbirth

\section{INTRODUCTION}

The urinary system undergoes significant structural and functional changes during normal pregnancy. Pregnancy has been regarded as a high-risk phase to women with underlying renal disease. ${ }^{1,2}$ In normal pregnancy as the cardiac output increases, there occurs an increase in the renal plasma flow and glomerular filtration rate, leading to hyperfiltration Those with underlying renal disorders are unable to adapt to these physiological changes. Hence leading to unfavourable fetomaternal outcomes. ${ }^{3}$
CKD is a heterogeneous group of renal dysfunctions with a GFR below $60 \mathrm{ml} / \mathrm{min}$, lasting for at least 3 months". 4,5 Due to its complex presentations, recently the term "obstetric nephrology" has been proposed to represent CKD in pregnancy. ${ }^{6}$ Globally its prevalence among women is estimated to be $11 \%-13 \% .^{7-9}$ In India, prevalence of $\mathrm{CKD}$ is found to be higher than their male counterparts i.e. between $16.3 \%$ and $19.1 \%$. $^{10-13}$ Specifically, prevalence among women of reproductive age worldwide is $0.1 \%$ to $3 \% .^{14}$ It carries a long asymptomatic period till significant renal damage occurs 
and symptoms appear. Hence there is a need to keep a high level of suspicion to make an early diagnosis since at all stages of CKD are associated with increased morbidity and mortality.

Conventionally, CKD is staged according to the worsening of glomerular filtration rate..$^{5}$ Recent, guidelines stage chronic kidney disease (CKD) according to levels serum creatinine. Mild, moderate, severe as creatinine levels $<1.5 \mathrm{mg} / \mathrm{dl}, \quad 1.5-3.5 \mathrm{mg} / \mathrm{dl}, \quad>3.5 \mathrm{mg} / \mathrm{dl}$ respectively. ${ }^{16,17}$ In normal pregnancy, due to hyperfiltration and increased creatinine clearance, the normal values is up to $0.5 \mathrm{mg} / \mathrm{dl}$. Any values greater than $0.9 \mathrm{mg} / \mathrm{dl}$ corresponds to underlying renal pathology and warrants detailed evaluation. Patients with an estimated GFR $\geq 1.4 \mathrm{mg} / \mathrm{dl}$ are at increased risk of progressive worsening of renal function. ${ }^{18}$ Certain pregnancy specific renal insult can complicate the already diseased kidneys of CKD patients. ${ }^{19,20}$ They may present with acute kidney injury (AKI) in post-partum and their progression depends upon the severity of underlying renal dysfunction irrespective of aetiology. ${ }^{21,22}$ With limited studies in Indian Subcontinent, there needs to be further studies to demonstrate the fetomaternal effects with the individual etiological subtypes.

\section{METHODS}

A retrospective cohort study was conducted among inpatient obstetric population of PGIMER and Dr. RML Hospital over a period of 3years and 4 months (January 2016-May 2019). Data was retrieved from case files taken from hospital medical record department. Cases included under study comprised of all inpatient obstetric population with known or recently diagnosed renal disorders irrespective of underlying etiology. Renal dysfunction was defined by deranged biochemical parameters (blood urea in $\mathrm{mg} / \mathrm{dl}$, serum creatinine in $\mathrm{mg} / \mathrm{dl}$ and serum uric acid in $\mathrm{mg} / \mathrm{dl}$ ) for at least 3 months, existence of proteinuria and presence /absence of complications like hypertension, cardiac failure, confirmation by presence of renal biopsy in prediagnosed cases. Observations with regard to all findings were done at time of first visit, during admission to hospital and during discharge. Among it, proteinuria was assessed subjectively using conventional dipsticks using PTBP (polytetrabromophenyl) as indicator. Those with proteinuria were subjected to confirmatory tests in form of 24 hour urinary protein ( $\mathrm{mg} /$ day). Urine routine microscopy and urine culture sensitivity were noted. Haemoglobin levels were noted for grading of anaemia (mild 10-11gm/dl, moderate 7-9gm/dl, severe $<7 \mathrm{gm} / \mathrm{dl}$ ). Blood pressure was noted as per records. As per hospital protocols, method followed included measurement in sitting position in left arm using mercury sphygmomanometer after 5 minutes of rest, using $140 / 90 \mathrm{mmHg}$ as cut off for defining hypertension, cardiac dysfunction confirmed after echocardiography. Note was made of obstetric history, medical/surgical history and family history. Intrapartum or postpartum complications. Obstetric history included time to first conception, gravida, parity, abortions, live births, still birth, ectopic, gestation age at termination and its mode, complications if any. Foetal outcome was defined by fetal weight measured in nearest kilograms on spring type weighing machine, Apgar score recorded by attending paediatrician, NICU stay if any and its duration. Computation and analysis of results was done using percentages, mean and proportions in tabular forms..

\section{RESULTS}

Out of 13 women studied, mean age was observed to be 25.69 years, whereas mean weight was $57.53 \mathrm{~kg}$. All patients had non consanguineous marriages and conceived spontaneously within 1 year of married life.

Table 1: Distribution of pregnancy outcome as per serum creatinine levels at first visit.

\begin{tabular}{|lllllll|}
\hline $\begin{array}{l}\text { Serum creatinine levels (at } \\
\text { first visit) }\end{array}$ & $\begin{array}{l}\text { Number of patients at } \\
\text { first visit }\end{array}$ & $\begin{array}{l}\text { Spontaneous } \\
\text { abortion }\end{array}$ & IUGR & $\begin{array}{l}\text { Preterm } \\
\text { delivery }\end{array}$ & $\begin{array}{l}\text { NICU } \\
\text { stay }\end{array}$ & $\begin{array}{l}\text { Perinatal } \\
\text { death }\end{array}$ \\
\hline$<0.5$ & 4 & 1 & 1 & 1 & 1 & 0 \\
\hline $0.5-0.9$ & 6 & 2 & 5 & 1 & 2 & 0 \\
\hline$>0.9$ & 2 & 2 & 2 & 0 & 1 & 0 \\
\hline
\end{tabular}

All, except one, pregnancies were booked and under regular follow up in antenatal clinics. Women were found to have their first visit to hospital in first, second and third trimester as $33.3 \%, 58.3 \%$ and $8.3 \%$ respectively. Among women booked at antenatal clinic, 7 out of 13 $(53.8 \%)$ were already diagnosed cases of renal dysfunction whereas rest $(46.2 \%)$ were diagnosed during antenatal visits. Out of multiparas, $60 \%$ had history of pregnancy induced hypertension in their previous pregnancies.

To begin with $38 \%$ of the patients had proteinuria at their first visits. Whereas, 14\% developed during pregnancy and $50 \%$ of women studied remained hypertensive in the post-partum phase irrespective of aetiology. Associated co-morbidities were observed in the form of secondary/renal hypertension and superimposed 
preeclampsia syndrome seen in $30 \%$ and $38 \%$ cases respectively. In postpartum phase, only one patient received magnesium sulphate prophylaxis for 24 hours. Among patients, only one presented with severe complications in form of cerebrovascular accident. Proteinuria as an indicator of renal function was found to be present in varying amounts in $38 \%$ patients at the first visit. This persisted till delivery and worsened in $46 \%$ cases. Among patients with pre-existing renal disease, cardiac dysfunction was diagnosed to be coexisting in $15.3 \%$ cases. On basis of obstetric history, $80 \%$ cases of spontaneous abortions were found to be present in those with high serum creatinine levels at the first visit. Of these, only $1(7.6 \%)$ had associated Mullerian anomaly in form of unicorn ate uterus with normal renal anatomy. With regard to fetal wellbeing, intrauterine growth restriction (as confirmed by ultrasound) was seen in $61.5 \%$ cases. Among term pregnancies, 1 out of 9 $(11.1 \%)$ landed up with poor biophysical profile, for which induction of labour was done. Average fetal weight was observed to be $2.26 \mathrm{~kg}$. Of them, 4 out of 13 (30\%) had NICU stay due to low birth weight and TTN (transient tachypnoea of new born) (Table 1).

\section{Table 2: Distribution of number of deliveries with} gestational age at termination.

\begin{tabular}{|lll|}
\hline $\begin{array}{l}\text { Gestational age } \\
\text { (in weeks) }\end{array}$ & Gestational age & $\begin{array}{l}\text { Number of } \\
\text { deliveries }\end{array}$ \\
\hline$<33+6$ & Early preterm & 2 \\
\hline $34-36+6$ & Late preterm & 2 \\
\hline $37-38+6$ & Early term & 9 \\
\hline $39-40+6$ & Full term & 0 \\
\hline$>41$ & Post dated & 0 \\
\hline
\end{tabular}

Table 3: Percentage distribution of severity of anaemia during course of pregnancy with CKD.

\begin{tabular}{|llll|}
\hline $\begin{array}{l}\text { Severity of } \\
\text { anaemia }\end{array}$ & $\begin{array}{l}\text { At first } \\
\text { visit }\end{array}$ & $\begin{array}{l}\text { At } \\
\text { admission }\end{array}$ & Postpartum \\
\hline $\begin{array}{l}\text { Severe } \\
<7 \mathrm{gm} / \mathrm{dl}\end{array}$ & $7 \%$ & $7 \%$ & 0 \\
\hline $\begin{array}{l}\text { Moderate } 7- \\
9 \mathrm{gm} / \mathrm{dl}\end{array}$ & $46 \%$ & $38 \%$ & $46 \%$ \\
\hline $\begin{array}{l}\text { Mild } 10- \\
11 \mathrm{gm} / \mathrm{dl}\end{array}$ & $38 \%$ & $30 \%$ & $38 \%$ \\
\hline
\end{tabular}

Majority of patients delivered at early term (61.5\%), whereas remaining $(30.6 \%)$ had preterm delivery-15.3\% as early preterm, another $15.3 \%$ as late preterm. Also, 1 out of $13(7.6 \%)$ had preterm intrauterine demise. Among patients, spontaneous onset of labour was observed in 10 out of $13(30 \%)$ cases, whereas 3 of $13(23 \%)$ were induced by PGE2 gel due to obstetric indications. Of the induced labours, only one had emergency caesarean due to non-progress of labour. Elective caesarean was carried out in $38 \%$ cases, including the one which was done on request. Another $8 \%$ included preterm emergency caesareans that led to iatrogenic prematurity (Table 2).
Among those operated, $16 \%$ had SSI (surgical site infection).

At first antenatal visit, anaemia was observed to be mild, moderate, severe in $46 \%, 38 \%, 7 \%$ cases respectively. Percentage of cases found to be anaemic at first visit showed improvement further at their admission and discharge (Table 3).

Average duration of stay was observed to be 17.9 days.

\section{DISCUSSION}

In today's world, with demographic expansion and increased high risk behavior, probability of death from CKD among young adults is increasing. ${ }^{23}$ Supporting the evidence, we observed the average of CKD cases studied was 25.6 years at presentation. With the lack of an updated registry system, the rising prevalence of CKD in young productive population gives a socioeconomic impact in developing countries like India. In this signifies a need for early and accurate diagnostic and treatment modalities to especially those at risk. But irrespective of ante-natal events, post-partum decline in kidney function has been observed. ${ }^{24}$

Previously, it was considered for the women with CKD to avoid pregnancy and allow termination in fear of getting the disease worsened. ${ }^{14}$ But with advances in obstetric care, pregnancy can be continued under supervision of a nephrologist and mode of termination can be decided as per obstetric point of view.

CKD is known to be associated with decreased fertility and poor reproductive outcomes, mostly attributed to the hypothalamic pituitary axis dysregulation. ${ }^{25}$ Whereas we observed $100 \%$ spontaneous conception rate in our study population, with all of them conceiving within the first year of marriage.

Preterm births refer to those before 37 weeks, whereas prematurity refers to immaturity to attain an organ functioning. Embryologically, $60 \%$ of nephrons differentiate in third trimester and delivery before term impairs this development process. ${ }^{26-28}$ Casey $\mathrm{C}$ et al, observed that preterm and early term birth had nearly twofold and 1.3-fold higher risks of developing CKD in adult life, respectively, compared with full term birth. ${ }^{26}$ We also observed all deliveries in these two categories only i.e. $61 \%$ early term and $30 \%$ preterm deliveries, none falling in full term or postdated category.

Seema $\mathrm{C}$ et al, conducted a retrospective analysis and identified $85 \%$ cases to be preterm deliveries with fetal survival rates $77 \% .^{29}$ In this regard, our study group had fewer i.e. $38 \%$ of preterm deliveries (including a preterm intrauterine device. With only one perinatal mortality noted, the fetal survival rate was significantly higher making up to $93 \%$. This can be attributed to better healthcare facilities and nursery care. 
In same study, it was observed that anemia was diagnosed in $46.1 \%$ cases and $7.7 \%$ of them required multiple blood transfusions. However, we observed anemia to be present among $76 \%$ cases at admission, out of which $7 \%$ required blood transfusion.

Mode of termination in our patients was individualized. Among cases, $30 \%$ went into term spontaneous onset of labor and had normal obstetric outcome. Whereas our cesarean rate was $46 \%$, which was slightly higher than seen in above study, with $30 \%$ incidence.

Anemia is highly prevalent in patients with CKD, reported in up to $50 \%$ of patients and severity depends upon the degree of renal dysfunction. ${ }^{30}$ In combination with dietary iron malabsorption and losses, erythropoietin deficiency is the main factor. ${ }^{31}$ Another reason cited is reduced availability for hematopoiesis due to reticuloendothelial blockade. In CKD patients, anemia is associated with adverse events (cardiovascular disease, infection, hospitalization, and mortality. ${ }^{32}$

Kidney disease improving global outcomes (KDIGO) defines severe anemia as hemoglobin $\leq 9 \mathrm{~g} / \mathrm{dl}$ because it is the level at which symptoms onset occurs. ${ }^{33,16}$ Accordingly, Katherine $\mathrm{G}$ et al, observed $13.7 \%$ cases of severe anemia, with mean length of stay being 6.4days.In contrast we found a greater incidence of anemia i.e. $46 \%$ of patients at admission(mean hemoglobin of $8.3 \mathrm{gm} \%$ ). Mean length of stay hence was observed in our case to be 17.9days. Apart from duration of neonate nursery stay, this was mainly due to maternal surgical site infection. ${ }^{34}$

Chronic kidney disease (CKD) is a major contributor to cardiovascular (CV) mortality. ${ }^{35}$ As the renal disease worsens, there is element of cardiac hypertrophy and fibrosis. This has been attributed to oxidative stress and reduced nitric oxide availability in cardiac myocytes. ${ }^{36}$ Izumaru $\mathrm{K}$ et al, observed cardiac remodeling in form of left ventricular hypertrophy $(\mathrm{LVH})$ and fibrosis, a feature common in CKD. ${ }^{37}$ This impedes the diffusion of oxygen and leads to apoptosis of cardiomyocytes and displacement of collagen fibers. Cardiac failure is becoming a leading cause of death in patients with CKD. We also observed $15 \%$ cases to be associated with preexisting cardiac lesions in form of rheumatic heart disease (mitral stenotic component) and dilated cardiomyopathy. However, their course was stable during pregnancy and postpartum. This concept highlights the need for routine screening of CKD patients for cardiac wellbeing.

Misra et al, observed $100 \%$ rate of preterm delivery in all patients with a diastolic blood pressure $>100 \mathrm{mmHg}$. They observed that of these, $35.5 \%$ cases of uncontrolled hypertension had iatrogenic preterm deliveries. ${ }^{38}$ Serum creatinine worsened in $32.5 \%$, more in those with high pre pregnancy values. Similarly, Seema $\mathrm{C}$ et al observed that $90 \%$ women developed hypertension during pregnancy in which $40 \%$ had mild hypertension and
$43.3 \%$ had severe hypertension requiring drug therapy. ${ }^{29}$ In meta-analysis conducted by Zhang JJ et al, greater odds of preeclampsia, premature delivery, small for gestational age/low birth weight were obtained in the patients with CKD. ${ }^{14}$ O'Shaughnessy MM et al made an observation of $33 \%$ of pregnancies complicated by preeclampsia and $27 \%$ by persistent increase in serum creatinine. Our findings were similar to the above studies as we found $38 \%$ of cases developed preeclampsia requiring medical therapy. Out of these, $40 \%$ had term deliveries, $40 \%$ had iatrogenic prematurity due to uncontrolled blood pressures and IUGR and 20\% had spontaneous preterm premature rupture of membranes. But in contrast with above study, we observed $61.5 \%$ had worsening of serum creatinine levels during pregnancy. Although none required dialysis, there arises a need that these patients should be meticulously followed postdelivery to timely manage and prevent progress to (End stage renal disease) ESRD.

O'Shaughnessy MM et al, studied on a obstetric population comprising $13.3 \%$ cases of membranous nephropathy, $9.3 \%$ of minimal change disease and $3.7 \%$ cases of focal segmental glomerulosclerosis. ${ }^{39}$ Among them, $13 \%$ of pregnancies resulted in perinatal death and $48 \%$ preterm deliveries. Whereas we observed a greater incidence of FSGS, minimal change disease and membranous nephropathy in $7.6 \%$ and $15.3 \%$ cases respectively.

Presence of a solitary kidney can be due to congenital agenesis, contralateral nonfunctioning kidney or spontaneous involution of a congenital dysplastic kidney. Renal agenesis refers to failure of embryonic renal bud differentiation. Steele SE et al, observed an incidence of $57.6 \%$ pregnant women with congenital single kidney. None had hypertension or proteinuria in first visit. Among them, urinary tract infection complicated 50\% of pregnancies and 35\% developed pre-eclampsia during course of their pregnancy. ${ }^{40}$ We studied 5 out of $13(38 \%)$ cases having pre-diagnosed solitary kidney. Of these $20 \%$ were known renal hypertensive and consequently developed superimposed preeclampsia and $20 \%$ suffered from symptomatic UTI (E. coli>105CFU).

\section{CONCLUSION}

Pregnancy with CKD is considered as a high-risk pregnancy. Despite recent advances in obstetric care, incidence of adverse fetomaternal outcome continues to be high in these women. For optimal pregnancy outcomes, an expert multidisciplinary team is required for their periconceptional disease optimization and follow up. Adverse effect of individual subtype of renal diseases in pregnancy requires further large studies. With hardly any studies on chronic kidney diseases in south Asian population specifically, there needs to be an updated registry system among the health care providers for a broader view of this health problem. 


\section{ACKNOWLEDGMENTS}

Authors would like to thank head of department for laying the foundation of this unique concept. Author would also like to thank his professors for constantly encouraging us to work upon this and helping us polishing the text.

\section{Funding: No funding sources}

Conflict of interest: None declared

Ethical approval: The study was approved by the Institutional Ethics Committee

\section{REFERENCES}

1. Hou S. Pregnancy in chronic renal insufficiency and end-stage renal disease. Am J Kidney Dis. 1999;33(2):235-52.

2. Nevis IF, Reitsma A, Dominic A, McDonald S, Thabane L, Akl EA, et al. Pregnancy outcomes in women with chronic kidney disease: a systematic review. Clin J Am Soc Nephrol. 2011;6(11):2587-98.

3. Nevis IF, Reitsma A, Dominic A, McDonald S, Thabane L, Akl EA, et al. Pregnancy outcomes in women with chronic kidney disease: a systematic review. Clin J Am Soc Nephrol. 2011;6(11):2587259.

4. Piccoli GB, Attini R, Vasario E, Conijn A, Biolcati M, D'Amico F, Consiglio V, et al. Pregnancy and chronic kidney disease: a challenge in all CKD stages. In J Am Soc Nephrol. 2010;5(5):844-55.

5. Hui D, Hladunewich MA. Chronic kidney disease and pregnancy. Obstet Gynecol. 2019;133(6):118294.

6. Piccoli GB, Zakharova E, Attini R, Ibarra Hernandez $\mathrm{M}$, Orozco Guillien A, Alrukhaimi $\mathrm{M}$, et al. Pregnancy in chronic kidney disease: need for higher awareness. A pragmatic review focused on what could be improved in the different CKD stages and phases. J Clin Med. 2018;7(11):415.

7. Piccoli GB, Attini R, Vasario E, Conijn A, Biolcati M, D'Amico F, et al. Pregnancy and chronic kidney disease: a challenge in all CKD stages. Clin $\mathbf{J}$ Am Soc Nephrol. 2010;5(5):844-55.

8. Hill NR, Fatoba ST, Oke JL, Hirst JA, O'Callaghan CA, Lasserson DS, et al. Global prevalence of chronic kidney disease - a systematic review and meta-analysis. PLoS One. 2016;11(7):e0158765.

9. Barrett PM, McCarthy FP, Kublickiene K, Evans M, Cormican S, Judge $\mathrm{C}$, et al. Adverse pregnancy outcomes and long-term risk of maternal renal disease: a systematic review and meta-analysis protocol. BMJ Open. 2019;9(5):e027180.

10. Anand S, Shivashankar R, Ali MK, Kondal D, Binukumar B, Montez-Rath ME, et al. Prevalence of chronic kidney disease in two major Indian cities and projections for associated cardiovascular disease. Kidney Int. 2015;88(1):178-85.

11. Anupama YJ, Uma G. Prevalence of chronic kidney disease among adults in a rural community in South
India: results from the kidney disease screening (KIDS) project. Indian J Nephrol. 2014;24(4):214.

12. Singh NP, Ingle GK, Saini VK, Jami A, Beniwal P, Lal M, et al. Prevalence of low glomerular filtration rate, proteinuria and associated risk factors in North India using Cockcroft-gault and modification of diet in renal disease equation: an observational, crosssectional study. BMC Nephrol. 2009;10:4.

13. Varma PP, Raman DK, Ramakrishnan TS, Singh P, Varma A. Prevalence of early stages of chronic kidney disease in apparently healthy central government employees in India. Nephrol Dial Transplant. 2010;25(9):3011-7.

14. Zhang JJ, Ma XX, Hao L, Liu LJ, Lv JC, Zhang H. A systematic review and meta-analysis of outcomes of pregnancy in CKD and CKD outcomes in pregnancy. Clin J Am Soc Nephrol. 2015;10(11):1964-78.

15. El Hafeez SA. Non-steroidal anti-inflammatory drugs among chronic kidney disease patients: an epidemiological study. J Egypt Public Health Assoc. 2019;94(1):8

16. Drueke TB, Parfrey PS. Summary of the KDIGO guideline on anemia and comment: reading between the (guide)line(s). Kidney Int. 2012;82:952-60.

17. Roberts M, Lindheimer MD, Davison JM. Altered glomerular perms selectivity to neutral dextrans and heteroporous membrane modeling in human pregnancy. Am J Physiol. 1996;270:F338.

18. Vellanki K. Pregnancy in chronic kidney disease. Adv Chronic Kidney Dis. 2013;20(3):223-8.

19. Nee PA, Bailey DJ, Todd V, Lewington AJ, Wootten AE, Sim KJ. Critical care in the emergency department: acute kidney injury. Emerg Med J. 2016;33(5):361-5.

20. Krane NK. Acute renal failure in pregnancy. Arch Intern Med. 1988;148(11):2347-57.

21. Schokker SA, Van Oostwaard MF, Melman EM, Van Kessel JP, Baharoglu MI, et al. Cerebrovascular, cardiovascular and renal hypertensive disease after hypertensive disorders of pregnancy. Pregnancy Hypertens. 2015;5(4):287-93.

22. Imbasciati E, Gregorini G, Cabiddu G, Gammaro L, Ambroso G, Del Giudice A. Pregnancy in CKD stages 3 to 5: fetal and maternal outcomes. Am J Kidney Dis. 2007;49(6):753-62.

23. Bowe B. Changes in the US burden of chronic kidney disease from 2002 to 2016: an analysis of the global burden of disease study. JAMA Netw Open. 2018;1(7):e184412.

24. Pillay C, Clark K. Postpartum care of women with renal disease. Best Pract Res Clin Obstet Gynaecol. 2019;pii:S1521-6934(19)30021-5.

25. Dumanski SM, Ahmed SB. Fertility and reproductive care in chronic kidney disease. J Nephrol. 2019;32(1):39-50.

26. Crump C, Sundquist J, Winkleby MA, Sundquist K. Preterm birth and risk of chronic kidney disease from childhood into mid-adulthood: national cohort study. BMJ. 2019;365:11346. 
27. Abitbol CL, Rodriguez MM. The long-term renal and cardiovascular consequences of prematurity. Nat Rev Nephrol. 2012;8:265-74.

28. Abitbol CL, DeFreitas MJ, Strauss J. Assessment of kidney function in preterm infants: lifelong implications. Pediatr Nephrol. 2016;31:2213-22.

29. Seema C. Pregnancy in chronic renal insufficiency: single center experience from North India. Arch Gynecol Obstet. 2009;279:691.

30. Garlo K. Severity of anemia predicts hospital length of stay but not readmission in patients with chronic kidney disease: a retrospective cohort study. Medicine (Baltimore). 2015;94(25):e964.

31. Hildegard Stancu S. Renal anemia and hydration status in non-dialysis chronic kidney disease: Is there a link. J Med Life. 2018;11(4):293-8.

32. Kuragano T, Mizusaki K, Kimura T, Nakanishi T. Anemia management considering the pathophysiology of elderly chronic kidney disease patients. Contrib Nephrol. 2019;198:135-43.

33. K/DOQI clinical practice guidelines for chronic kidney disease: evaluation, classification, and stratification. Am J Kidney Dis. 2002;39:S1-S266.

34. Hasan M, Sutradhar I, Gupta RD, Sarker MM. Prevalence of chronic kidney disease in South Asia: a systematic review. BMC Nephrol. 2018;19(1):291.

35. Amador-Martínez. Reduced endothelial nitric oxide synthase activation contributes to cardiovascular injury during chronic kidney disease progression. Am J Physiol Renal Physiol. 2019.

36. Izumaru K. Reduced estimated GFR and cardiac remodeling: a population-based autopsy study. Am J Kidney Dis. 2019.

37. Misra R. Pregnancy with chronic kidney disease: Outcome in Indian women. J Women Health. 2004;12:1019-25.

38. O'Shaughnessy MM. Pregnancy outcomes in patients with glomerular disease attending a single academic center in North Carolina. Am J Nephrol. 2017;45(5):442-51.

39. Laurichesse Delmas H. Congenital unilateral renal agenesis: prevalence, prenatal diagnosis, associated anomalies. Data from two birth-defect registries. Birth Defects Res. 2017;109(15):1204-11.

40. Steele SE, Terry JE, Page LM, Girling JC. Pregnancy in women known to be living with a single kidney. Obstet Med. 2019;12(1):22-6.

Cite this article as: Gupta P, Chawla I, Ara A, Malik R. Chronic kidney disease in pregnancy and fetomaternal outcome. Int J Reprod Contracept Obstet Gynecol 2019;8:3518-23. 